Horm. metabol. Res. 16 (1984) 163-167

(C) Georg Thieme Verlag Stuttgart • New York

\title{
Development of Individual Insulin Infusion Profiles for Open Loop Infusion Systems*
}

\author{
T. Strack ${ }^{+}$, U. Krause, G. Schulz, J. Beyer, F. Beutelspacher and J. Nagel \\ Abteilung für Innere Medizin, Endokrinologie und Stoffwechsel, Universitätskliniken Mainz, Mainz, and \\ Zentralinstitut für Biomedizinische Technik, Universität Erlangen-Nürnberg, Institut für Biomedizinische \\ Technik, Universität Stuttgart, Stuttgart, Germany
}

\begin{abstract}
Summary
A computer controlled syringe-type insulin infusion pump storing up to 254 different infusion rates, eight different meal programs and two different basal rates automatically changeable during $24 \mathrm{~h}$ in EPROM was used for insulin infusion applying a wavy step profile. This profile approaching the physiological postprandial insulin secretion of the Bcell was calculated by an algorithm following the biphasic insulin secretion model proposed by E. Cerasi.

The computer program for the open loop infusion device simulated the feed-back structure of a closed loop insulin secretion control by an algorithm based upon a theoretical postprandial blood sugar profile.

Fifteen unstable juvenile onset insulin requiring diabetics could be well controlled after two to three days of an intravenous open loop insulin infusion program. The programs consisted of two constant basal rates and superimposed wavy step profile programs activated at the beginning of each meal.

The preabsorptive bolus or cephalic phase was an additional tool both for improved postprandial blood sugar control and further reduction of insulin consumption.

The programmable insulin infusion device proved as a valuable tool for the study of a sophisticated insulin infusion profile suitable as well for open loop as for closed loop insulin infusion systems.
\end{abstract}

Key-Words: Preprogrammed Insulin Infusion - Algorithms for Insulin Infusion Profiles - Intravenous Insulin Therapy Artificial Pancreas - Unstable Type-1-Diabetics - Open-Loop Diabetes Control

\section{Introduction}

Closed loop insulin infusion systems are able to regulate the blood sugar level of juvenile insulin dependent diabetics (IDD's) within a normoglycaemic range without counterregulatory glucose infusion (Pfeiffer, Thum and Clemens 1974). The major disadvantages of these artificial endocrine pancreata are their considerable size, the extensive servicing program, the insufficient reliability of the blood

\footnotetext{
* Supported by the German BMFT (Dismed 13)

+ This work contains part of the doctoral thesis of T. Strack
}

glucose sensor, and the sustained loss of blood. Thus, for the present time, the use of closed loop systems is restricted to short-term inpatient treatment (Horwitz 1980; Beyer, Wolf, Cordes and Hassinger 1979; Lambert, Buysschaert, Marchand, Diwrard, Wojcik and Lambotte 1978).

An acceptable metabolic control similar to the Biostator TM can also be achieved by simple open loop insulin infusion devices providing a constant basal rate and rectangular or bolus-type profiles to cover the postprandial insulin need

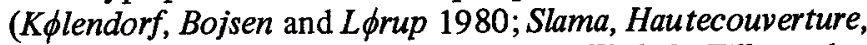
Assan and Tchobroutsky 1974;Perlman, Ehrlich, Filler and Albisser 1981).

However, the large number of blood sugar controls and variations in insulin doses is not reasonable for a long-term outpatient treatment. Without close-meshed blood sugar control,instability of the metabolic condition and insulin requirement tend to increase, the latter causing increasing insensitivity to exogenous insulin (Gavin, Roth, Neville, DeMeyts and Buell 1974; Smith 1980).

This paper describes the development and programming of postprandial insulin infusion profiles which promise to stabilize the daily blood sugar range and to minimize insulin requirement in IDDM more than the conventional open loop insulin infusion systems.

\section{Materials and Methods}

\section{Patients}

15 type-I-diabetics (Tab. 1) were studied for three days (Fig. 1). The patients received standard diets consisting of $40 \%$ fat, $20 \%$ protein, and $40 \%$ carbohydrates. The daily food intake was distributed over six meals per day. Programs with and without cephalic phase were tested in six of the 15 patients using the same insulin dosage for both programs.

\section{Materials}

The insulin infusion system used in this study has the external dimensions $19.5 \times 7.8 \times 5.0 \mathrm{~cm}$ and has a weight of $800 \mathrm{~g} \mathrm{(Fig.} \mathrm{2).}$ An electric stepping motor propells the piston of a reusable

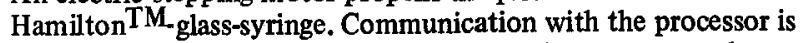
possible via a keyboard; basal rates and meal programs can be activated by typing a numerical code. A LCD indicates time or activated program and basal rates. 
Table 1 Clinical data of 15 patients treated with IPIS

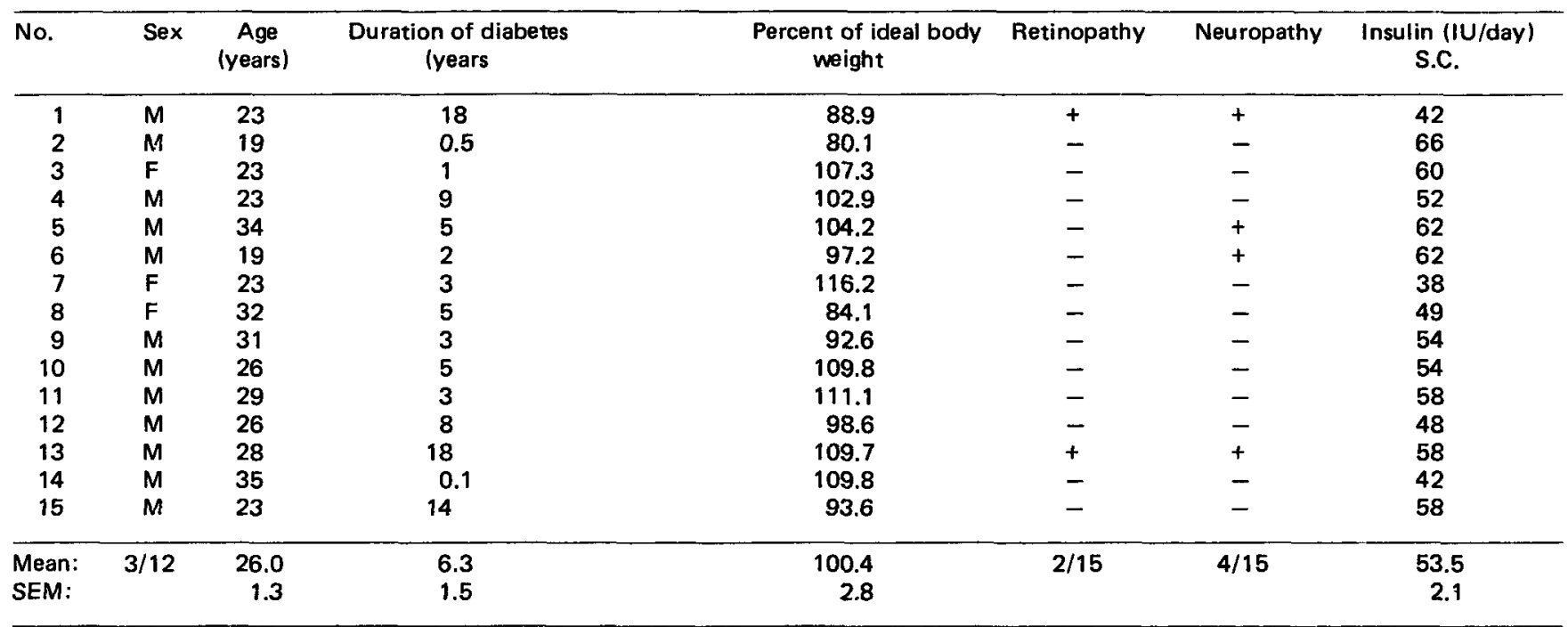

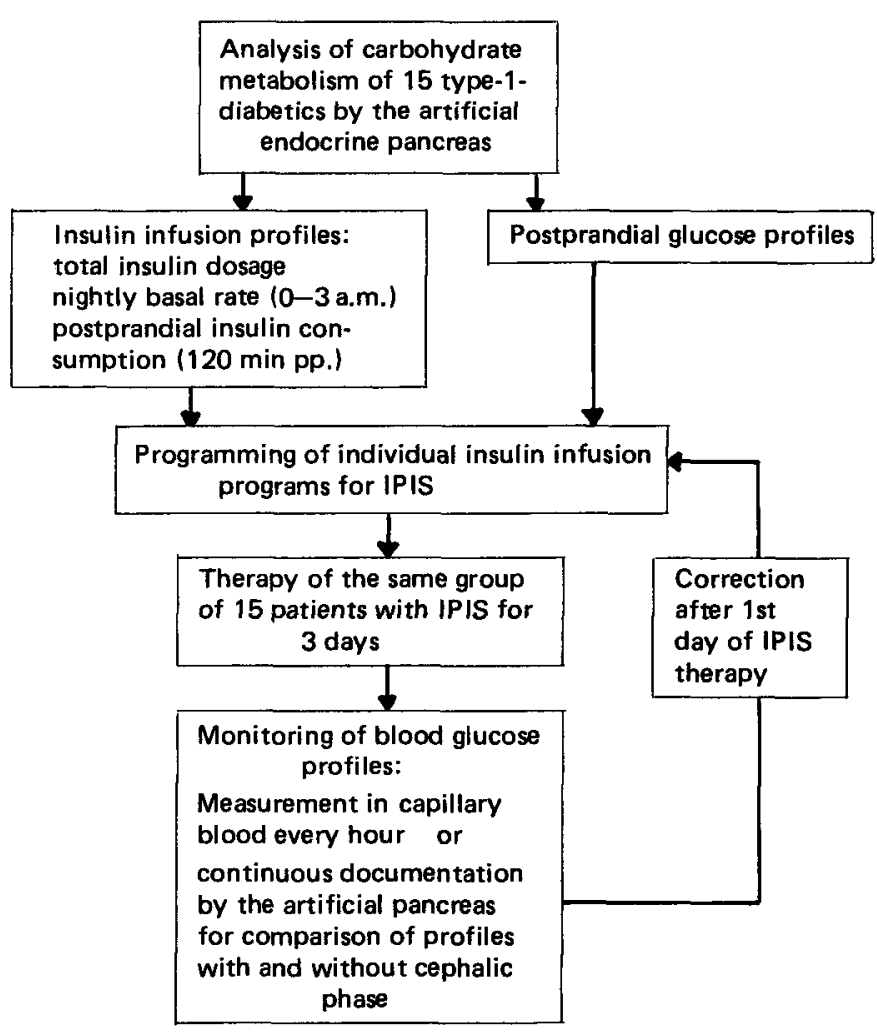

Fig. 1 Flow diagram of the study protocol

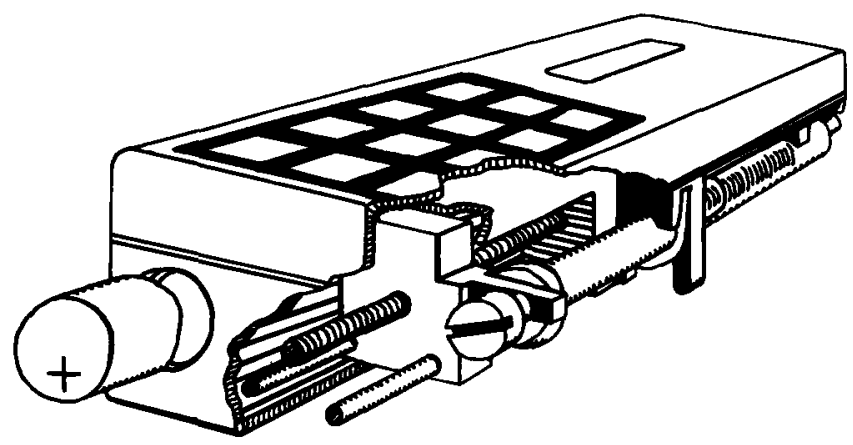

Prototype of an individually programmed insulin infusion system (IPIS)

Fig. 2 Individually programmed insulin infusion system (IPIS)

Two basal rates automatically change during 24 h. 254 different infusion rates $(0.1 \mu \mathrm{l} / \mathrm{min}$ to $25 \mu \mathrm{l} / \mathrm{min})$ can be read back following a mode preprogrammed in EPROM which stores eight meal programs. One program has a duration of 2.5 hours, six programs last two hours and, finally, there is a 30 minutes program for reserve. EPROM was programmed by an Apple II plus computer.

The catheter (Siemens AG) was inserted into a deep brachial vein. The blood sugar was measured hourly in capillary blood using an Y23a Glucose Analyzer TM (GOD method). For more precise comparison of the different insulin infusion profiles a glucose controlled insulin infusion system (Biostator $\mathrm{TM}$ ) monitored venous blood glucose levels in simulated feed back. 


\section{Methods}

The model of the step profile tries to simulate the dynamics of the phy siological insulin secretion without consideration for the morphological details (Cerasi, Fick and Rudemo 1974). The insulin infusion rate (IIR) is proportional to three factors:

- A hyperbolic tangent function $(\mathrm{f}(\mathrm{g}))$ calculating the initial phase of IIR

- an exponential function (exp(p)) computing the second phase of IIR

- an exponential function (exp(-b)) simulating the refractory period of the islets of Langerhans.

Thus the formula reads as follows:

$$
\text { IIR } f(g) x \exp (p-b)
$$

For the computation by Apple II the differential equations advanced by Cerasi (1967) have to be integrated.

For $\mathrm{p}(\mathrm{t})$ follows:

$$
\begin{aligned}
& p(t)=k_{p} \times f(g)_{t_{i-1}} \times\left(T_{p} \times T_{p 1} \times\left(1-\exp \left(-\frac{t_{i}}{T_{p}}\right)\right)\right. \\
& -\frac{T_{p} \times\left(T_{p 1}\right)^{2}}{T_{p 1}-T_{p}} \times\left(\exp \left(-\frac{t_{i}}{T_{p}}\right)-\exp \left(-\frac{t_{i}}{T_{p 1}}\right)\right)
\end{aligned}
$$

whereby $T_{p}, T_{p 1}$ and $k_{p}$ are constants. A similar equation counts for $b(t)$ :

$$
\begin{aligned}
& b(t)=K_{b} \times I I R_{t_{i}-1} \times\left(T_{b} \times T_{b 1} \times\left(1-\exp \left(-\frac{t_{i}}{T_{b}}\right)\right)\right. \\
& \left.-\frac{T_{b} \times\left(T_{b 1}\right)^{2}}{T_{b 1}-T_{b}} \times\left(\exp \left(-\frac{t_{i}}{T_{b}}\right)-\exp \left(-\frac{t_{i}}{T_{b 1}}\right)\right)\right)
\end{aligned}
$$

whereby $T_{b}, T_{b 1}$ and $k_{b}$ are constants.

Since the open loop insulin infusion system does not measure blood sugar a rigid model has to simulate the postprandial behaviour of the blood sugar concentration; its ascending part simulates the slow rise of blood sugar after an oral food intake:

$\mathrm{BS}_{\text {asc. }}=\frac{\mathrm{C}_{1} \times \exp \left(\mathrm{k}_{1} \times \mathrm{t}_{\mathrm{i}}\right)-\mathrm{C}_{2} \times \exp \left(\mathrm{k}_{2} \times \mathrm{t}_{\mathrm{i}}\right)}{\mathrm{C}_{1} \times \exp \left(\mathrm{k}_{1} \times \mathrm{t}_{\mathrm{i}}\right)+\mathrm{C}_{2} \times \exp \left(\mathrm{k}_{2} \times \mathrm{t}_{\mathrm{i}}\right)}$

whereby $C_{1}, C_{2}, k_{1}$ and $k_{2}$ are constants.

The descending part of the curve takes the blood sugar lowering effect of the insulin infused into account:

$\mathrm{BS}_{\text {desc. }}=\mathrm{C}_{3} \times \exp \left(\mathrm{k}_{3} \times \mathrm{t}_{\mathrm{i}}\right)$

whereby $C_{3}$ and $k_{3}$ are constants.

Thus the formula for the simulated postprandial blood sugar curve reads as follows:

$\mathrm{BS}=\mathrm{BM} \times \mathrm{BS}_{\mathrm{asc}} \times \mathrm{BS}_{\text {desc }}$.

whereby $\mathrm{BM}$ is a factor which is proportional to the amount of carbohydrates taken in.

The sigmoidal dose-response curve is approximated by a hyperbolic tangent function:

$\mathrm{f}(\mathrm{g})=\tanh (\mathrm{G})$

whereby $G=A \times \exp (K \times B S)$,

whereby $A$ and $K$ are constants.

Our constants were empirically determined by analysis of Biostator ${ }^{T M}$ data.

This model merely considers the insulin secretion characteristics modulated by a blood sugar rise: The preabsorptive insulin secro tion or cephalic phase of insulin secretion is presumably controlled by neural and gastrohormonal mechanisms (Grossman 1979; Brown and Otte 1978; Berthoud, Bereiter, Trimble, Siegel and Jeanrenaud 1981) simulated in this program by an initial 2-minutes IIR bolus. The values of the blood sugar curve and of the corresponding insulin infusion rate are computed for every minute (F ig. 3); IIR is graphically monitored. Both values are used for the computation of the next following IIR.

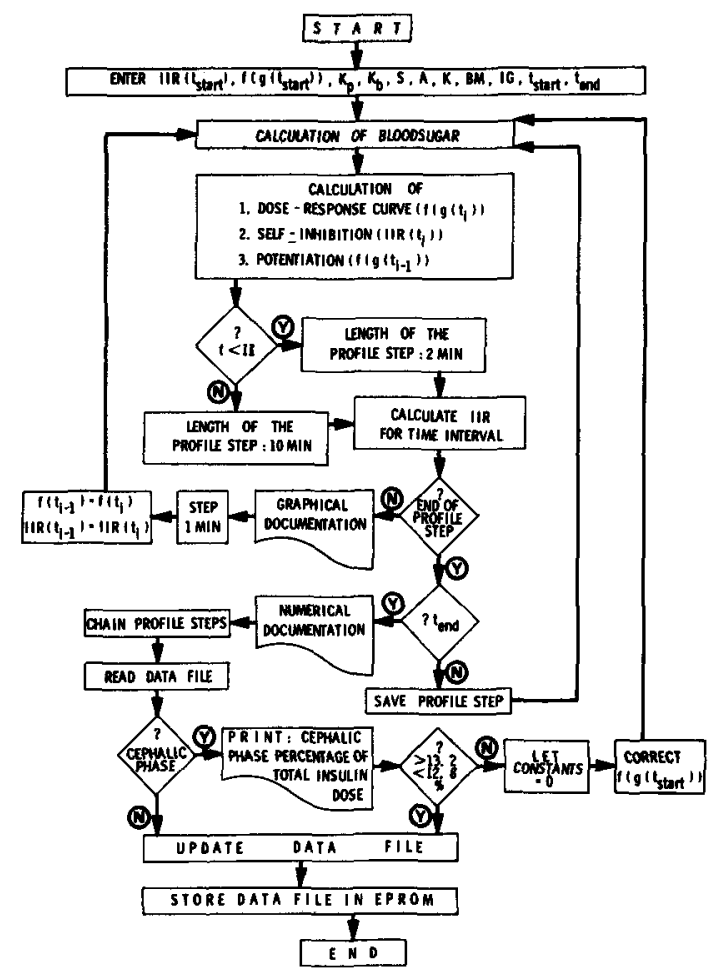

Fig. 3 Flow diagram of the computer algorithm; $t_{\text {end }}$ and $t_{\text {start }}$ determine the duration of the program; IIR ( $\left.t_{s t a r t}\right)$ is always $\left.0, f\left(g / t_{\text {start }}\right)\right)$ is either 0 or any value for the cephalic phase program; all other constants are individually determined by analysis of Biostator TM data.

Two-minute blocks are computed for the first ten minutes to allow for the cephalic phase which has a duration of 2 minutes. All other values are successively averaged over ten minutes; the mean values form ten-minute blocks for the following insulin infusion. When the algorithm has passed through the scheduled duration of the program the IIR-blocks and their sum are numerically displayed on the monitor screen.

The insulin dose was calculated according to a preceding analysis of metabolism by the artificial pancreas.

The preabsorptive bolus is created by an adequate choice of the initial value of $f(g)$ without disturbing the following algorithm. Successive varying of the height of the peak ensures a certain ratio of the preabsorptive bolus to the total amount of the infusion program: $13 \% \pm 0.2 \%$.

Finally, the data are arranged in a chain and stored in a floppy disk from where they can always be read back for transfer to EPROM.

\section{Mathematical Results}

If the algorithm is based upon an intravenous glucose infusion the well known biphasic insulin infusion profile results (Fig. 4). A parabolic curve of sixth order was chosen for the presented example. The infusion was calculated for two minute steps. For the same choice of constants but with a modified formula copying the blood sugar profile after oral carbohydrate ingestion, the algorithm calculates a different 


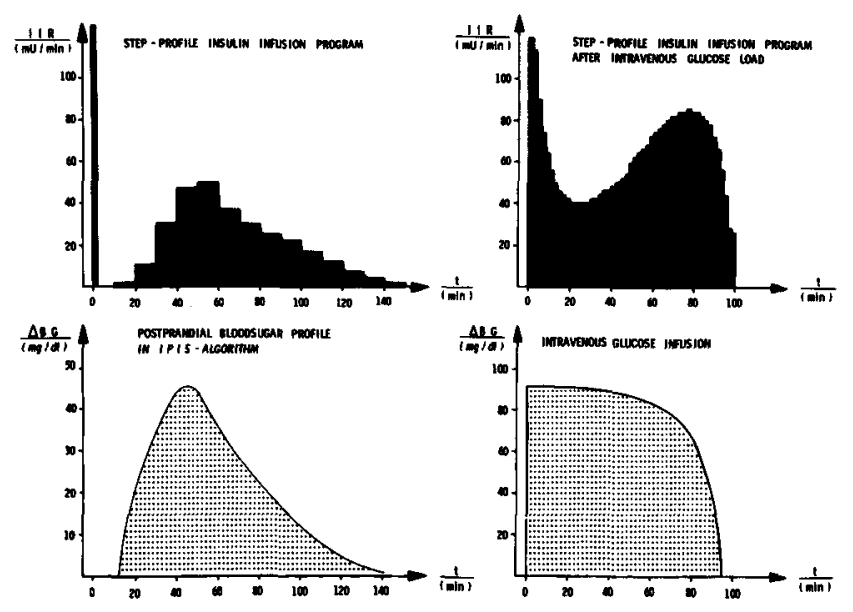

Fig. 4 Individually programmed insulin infusion profiles, calculated for two different types of glucose ingestion
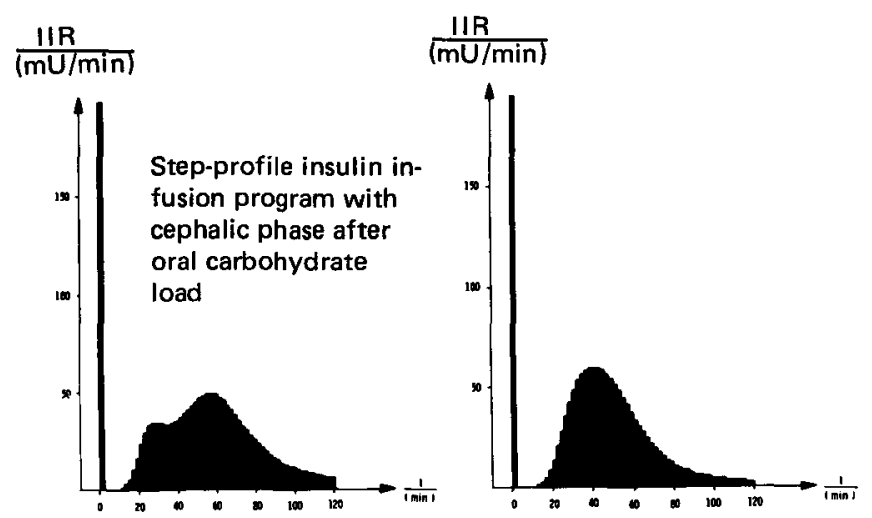

Fig. 5 Individually programmed step-profiles for an oral glucose load, with cephalic phase insulin infusion; eight IU are infused by both programs

insulin infusion profile (Fig. 5, left): it is also characterized by 2 peaks, the first peak, however, being lower and about 25 minutes delayed. Rise and decrease are distinctly slower, and the two peaks tend to fuse. This last feature is boosted by reducing the difference of $T_{p}$ and $T_{p} 1$ (Fig. 5 , right): The formerly biphasic profile becomes monophasic being in accordance with experimental results (Pfeiffer and Ziegler 1969; Chacra, Fujita, Herron and Seltzer 1978). This monophasic insulin infusion pattern for the calculation of the more crude infusion profiles based upon ten minute blocks (Fig. 4). It is also well known that a non glucose depending preabsorptive insulin secretion can be observed before oral food intake. So an initial two minutes peak simulates this feature of the natural insulin secretion.

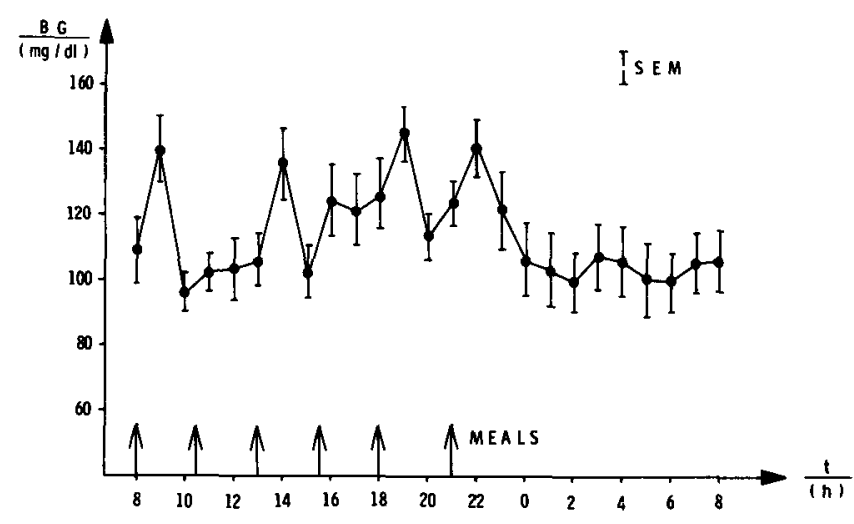

Fig. $624 \mathrm{~h}$ blood sugar profile of 15 IDD's treated with IPIS

\section{Clinical Results}

The insulin consumption could significantly $(\mathrm{P}<0.05)$ be lowered by individual step-profiles compared to the artificial pancreas: $49.7 \mathrm{IE} / \mathrm{d}$ vs $64.9 \mathrm{IE} / \mathrm{d}(\mathrm{n}=15)$. The blood glucose level averaged $113.6 \mathrm{mg} / \mathrm{dl} \pm 9.5 \mathrm{mg} / \mathrm{dl}$ (SEM, $\mathrm{n}=15$ ) with IPIS (Fig. 6). The M-value (Schlichtkrull, Munch and Jersild 1965) averaged $10.4 \pm 0.5$ (SEM, $\mathrm{n}=15$ ), the MAGE (Service, Molnar, Rosevear and Ackerman 1970) averaged $33.0 \mathrm{mg} / \mathrm{dl} \pm 2.8 \mathrm{mg} / \mathrm{dl}(\mathrm{SEM}, \mathrm{n}=15)$. The cephalic insulin infusion additionally stabilized the postprandial blood sugar oscillations. The mean blood sugar excursion, measured from the starting point of the meal, was significantly $(P<0.01, n=6)$ lower if a cephalic phase insulin infusion preceded the individual step-profiles: $0.8 \mathrm{mg} / \mathrm{dl} / 150 \mathrm{~min}$ vs $14.3 \mathrm{mg} / \mathrm{dl} / 150 \mathrm{~min}$.

\section{Discussion}

Our results demonstrate that the algorithm is able to produce any desired profile including those with cephalic insulin infusion. The choice of constants enables the programming of an infusion profile considering physiologic conditions. The cephalic phase insulin infusion possibly adds an insulin-saving effect suggesting that a sophisticated insulin infusion program is able to achieve both normoglycaemia and further reduction of insulin requirements.

However, the infusion pump used is too big and heavy for long-term outpatient treatment of IDD's but newer developments (Klein and Slama 1980) demonstrate that programmable insulin delivery systems can be reduced to reasonable dimensions.

The results gained under clinical conditions show the following considerable facts: 
1. After carbohydrate intake, the insulin infusion rate has rapidly to be raised, for instance in the sense of a preabsorptive bolus. The latter should consist of about $10 \%$ of the total amount of insulin and should be infused during 2 to 4 minutes.

2. About 30 to 40 minutes after the beginning of the infusion program, the second peak of the insulin infusion should be reached. Subsequently, the infusion rates should decrease to less then $40 \%$ after 60 to 70 minutes and less than $20 \%$ after 100 to 120 minutes.

3. The infusion program should have a minimal duration of 120 minutes.

These conclusions for the wavy step profile are important both for the algorithms of extracorporal closed loop system and for the programming of implantable open loop insulin delivery systems.

\section{References}

Berthoud, H.R., D.A. Bereiter, E.R. Trimble, E.G. Siegel, B. Jeanrenaud: Cephalic phase and reflex insulin secretion. Diabetologia 20: 393-401 (1981)

Beyer, J., $E$. Wolf, $U$. Cordes, $W$. Hassinger: The artificial beta cell (BIOSTATORTM) in the adjustment of instable diabetics Results after 20 months. Horm. Metab. Res. (Suppl. 8): 127-131 (1979)

Brown, J.C., S.C. Otte: Gastrointestinal hormones and control of insulin secretion. Diabetes 27: 782-787 (1978)

Cerasi, E.: An analogue computer model for the insulin response to glucose infusion. Acta endocrinologica 55: 163-183 (1967)

Cerasi, E., G. Fick, M. Rudemo: A mathematical model for the glucose induced insulin release in man. Eur. J. Clin. Invest. 4: 267-278 (1974)
Chacra, A.R., Y. Fujita, A.L. Herron, H.S. Seltzer: Uniphasic insulin secretory response in the pancreatic vein of dogs after an enteric glucose load. Diabetes 27:21-26 (1978)

Gavin, J.R., J. Roth, I.M. Neville, P. DeMeyts, D.N. Bull: Insulin dependent regulation of insulin receptor concentration: a direct demonstration in cell culture. Proc. Nat. Ac. Sci. USA 71: 84-88 (1974)

Grossman, M.I.: Neural and hormonal regulation of the intestinal function: an overview. Ann. Rev. Physiol. 41: 27-33 (1979)

Horwitz, D.L.: The artificial beta cell for treatment of diabetes mellitus. Int. J. Art. Organs 3: 136-138 (1980)

Klein, J.C., G. Slama: A sophisticated programmable miniaturized pump for insulin delivery. Med. Progr. Technol. 7: 193-197 (1980)

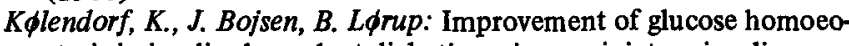
stasis in insulin dependent diabetics using a miniature insulin infusion pump with a fixed profile. Diabetologia 18: 141-145 (1980)

Lambert, A.E., M. Buysschaert, E. Marchand, M. Diwrard, S. Wojcik, L. Lambotte: Determination of insulin requirements in brittle diabetic patients by the artificial pancreas. Diabetes 27: 825833 (1978)

Perlman, K., R.M. Ehrlich, R.M. Filler, A.M. Albisser: Wave form requirements for metabolic normalization with continuous intravenous insulin delivery in man. Diabetes 30: 710-717 (1981)

Pfeiffer, E.F., R. Ziegler: Insulinsekretion in vivo. In: Handbuch des Diabetes mellitus, Band 1, Ed. Pfeiffer. München (1969), p. 221-228

Pfeiffer, E.F., C. Thum, A.H. Clemens: The artificial beta cell a continuous control of blood sugar by external regulation of insulin infusion (glucose controlled insulin infusion system). Horm. Metab. Res. 6: 339-342 (1974)

Schlichtkrull, J., O. Munch, M. Jersild: The M-value, an index of blood sugar control in diabetes. Acta Medica Scandinavia 177: 95-102 (1965)

Service, F.J., G.D. Molnar, J.N. Rosevear, E. Ackerman, L.C. Gatewood, W.J. Taylor: Mean amplitude of glycaemic excursions, a measure of diabetic instability. Diabetes 19: 644-655 (1970)

Slama, G., M. Hautecouverture, $R$. Assan, G. Tchobroutsky: One to five days of continuous intravenous insulin infusion on seven diabetic patients. Diabetes 23: 732-738 (1974)

Smith, U.: Regulation of the numbers of insulin receptors in human fat cells. Acta Endocrinologica 239, Suppl.: 19-22 (1980)

Requests for reprints should be addressed to: Dr. U. Krause, Abteilung für Endokrinologie, Klinikum der Johannes-Gutenberg-Universität, Langenbeckstr. 1, D-6500 Mainz (Germany) 